\title{
EDITORIAL
}

\section{Teleradiology- a cyber cafe approach}

\author{
Chander Mohan, SM \\ Director, Department of Interventional Radiology, BLK Super Speciality Hospital, New Delhi, India. \\ E-mail: brigcmohan@gmail.com
}

Dear colleagues,

Many technological advancements over the last three decades have made the specialty of radiodiagnosis the most sought after specialty. In fact, radiology has become an indispensable tool of health care.

The amount of information available on various imaging modalities is ever expanding. It is a challenge for radiologists to keep pace with newer applications and their optimal clinical applications. The various imaging modalities preferred by clinical colleagues from other specialties necessitate that we use cutting edge technology and contribute more than others to stay relevant and central to the health-care team. There is an acute shortage of general radiologists due to the stagnation in a number of faculty positions for radiologists in spite of ever increasing number of imaging modalities and quantum increase in workload. This scenario is worse for subspecialty radiologists who are working mostly in tertiary centers and large academic institutions.

The present day radiologist has to analyze large volumes of data being generated by imaging. The plethora of studies and need for comparative assessment has placed a significant burden on the workload of radiologists. This shortage is more acute in remote areas and in institutions providing primary and secondary level of care.

To meet the ever-increasing demand, teleradiology plays a significant role in providing diagnostic radiological services to remote and rural areas and setups who do not have radiologists. In fact, hospitals with general radiological services are using it to seek a second opinion. It also enables round-the-clock availability of radiologists along with the cost saving for the administrators.

Notwithstanding its various advantages, teleradiology has transformed the Radiology Department into a setup with multiple cubicles similar to cyber cafes of a bygone era equipped with high-resolution workstations. These centers could involve radiologists working in isolated corners, sometimes even in basements. This situation is further complicated by the pressure to work faster and adhere to a prescribed turnaround time with greater accuracy. The pressure from administrators for whom these are profit-making ventures would result in reduced interaction with patients and clinical colleagues. The monotony of work could lead to loss of enthusiasm for work and reduced professional satisfaction. This would also result in diminished support within the department, fewer professional relationships, and a feeling of isolation. This could result in a radiologist "running out of steam." This issue needs to be addressed early as radiology may lose its status as a desirable specialty with a good work-life balance. The administrators must encourage the radiologists to work together and attend clinicoradiological or tumor board meetings regularly. Radiologists also need to take the initiative to interact with clinical colleagues and be willing to shoulder clinical responsibility. This could even be at odd hours to promote their subspecialty and help make radiology a more clinically oriented specialty.

However, issues such as incompatibility between teleradiology equipment, resolution of imaging workstations, unreadable scans due to poor image quality, incomplete studies, lack of relevant clinical information, and lack of feedback are issues that affect the quality of telereporting.

Moreover, regulatory issues such as registration and accreditation of radiologists at places where telereporting is being sought, increasing demand from patients to interact with radiologists reporting the study, internal requirement of institutions, accessibility of patient records, reimbursement by medical insurance for services utilizing

This is an open access article distributed under the terms of the Creative Commons Attribution-NonCommercial-ShareAlike 3.0 License, which allows others to remix, tweak, and build upon the work non-commercially, as long as the author is credited and the new creations are licensed under the identical terms.

\begin{tabular}{|l|l|}
\hline \multicolumn{2}{|c|}{ Access this article online } \\
\hline Quick Response Code: & \\
\hline & Website: \\
& www.ijri.org \\
\cline { 2 - 3 } & Dol: \\
\hline
\end{tabular}

Cite this article as: Mohan C. Teleradiology- a cyber cafe approach. Indian J Radiol Imaging 2016;26:159-60. 
teleradiology, and responsibilities in case of legal issues need to be addressed, and clear policies and processes should be laid down so that the full potential of teleradiology can be achieved. There are a limited number of institutions and centers providing high-quality teleradiology services and ensuring all compliances are met. Members of the radiology and imaging association, as a vibrant body, can take the lead to engage with stakeholders and policymakers in formulating comprehensive guidelines and policies involving teleradiology services in the country. 